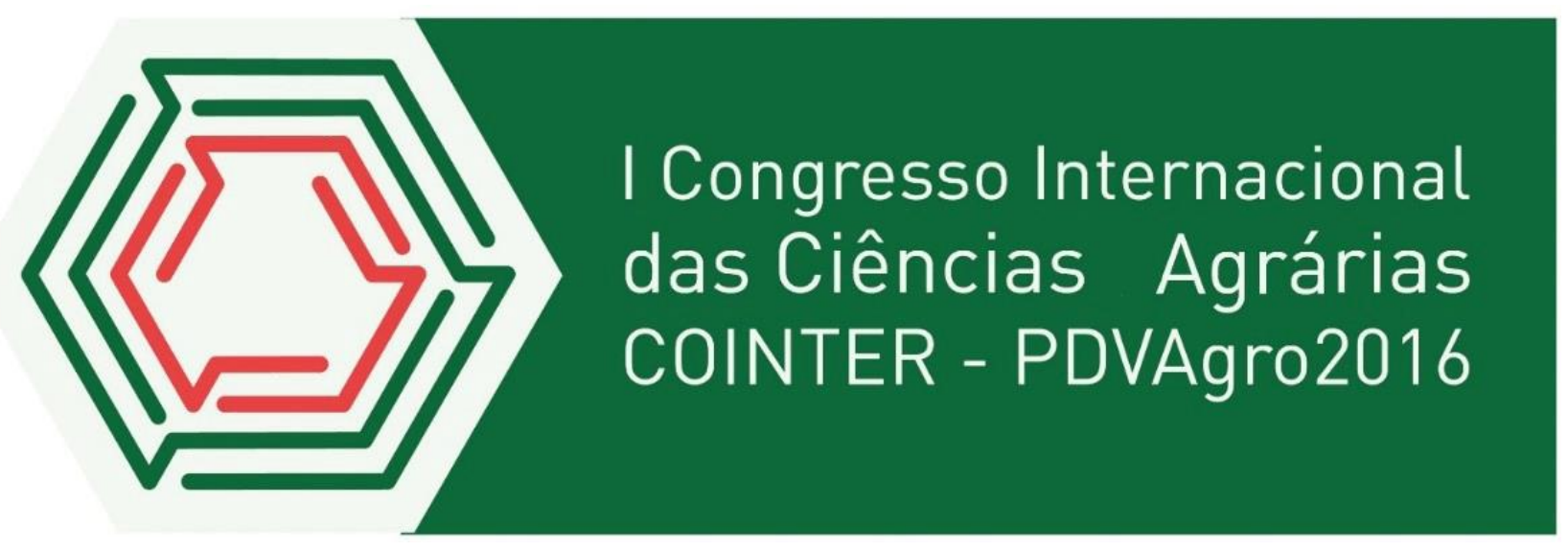

\title{
DESEMPENHO PRODUTIVO DE GENÓTIPOS DE BERINJELA CULTIVADOS EM SISTEMA ORGÂNICO
}

\author{
Apresentação: Comunicação Oral \\ José Carlos da Costa ${ }^{1}$; Severino Ramos da Costa ${ }^{2}$; Luiz Evandro de Lima ${ }^{3}$ Dimas Menezes ${ }^{4}$
}

\section{Resumo}

As iniciativas que buscam conciliar a produção agrícola com a conservação ambiental e os preceitos da segurança alimentar ganham cada vez mais espaço. Produtos orgânicos, agroecológicos, ambientalmente limpos ou de alto valor biológico são apresentados como frutos da agricultura sustentável. A berinjela, Solanum melongena L. é uma espécie que se encontra em fase de expansão no que se refere a importância agronômica e social, principalmente, pelas propriedades medicinais dos seus frutos na diminuição dos níveis de colesterol e pressão arterial. Este trabalho teve como objetivo avaliar genótipos de berinjela em sistema de cultivo orgânico, identificando os mais adaptados à Mesorregião da Mata Pernambucana. O experimento foi conduzido no decorrer do ano de 2012 e 2013, na área experimental da Estação Experimental Luiz Jorge da Gama Wanderley - IPA em Vitória de Santo Antão, PE, localizada na Mesorregião da Mata Pernambucana. Foram avaliadas duas cultivares de polinização aberta e seis híbridos de berinjela. Os genótipos foram avaliados em sistema de sucessão agroecológica conduzidos em delineamento de blocos casualizados. A parcela útil foi constituída por uma área de $4,8 \mathrm{~m}^{2}$ contendo seis plantas, transplantadas no espaçamento de $1,0 \mathrm{~m}$ x $0,8 \mathrm{~m}$, em seis repetições. As variáveis estimativas foram, diâmetro médio dos frutos, comprimento médio dos frutos, massa média dos frutos por planta, número de frutos por planta e produção média de frutos por planta. Os híbridos Rochelle, Viollete e Blanca apresentaram melhores resultados para massa dos frutos e produção de frutos por planta. Foi observada a superioridade na produtividade dos híbridos sobre as cultivares de polinização aberta no sistema de produção orgânica. Apesar desses híbridos apresentarem melhores resultados de produtividade, eles não são tão cultivados em Pernambuco, porque o formato e coloração dos frutos ainda não são bem aceitos pelos consumidores.

Palavras-Chave: Solanum melongena L.; orgânicos; híbridos; cultivares.

\section{Introdução}

A berinjela, Solanum melongena L., é uma hortaliça que pertence à família das solanáceas.

\footnotetext{
${ }^{1}$ Mestre, IFPE-Campus Vitória, jose.costa@vitória.ifpe.edu.br

${ }^{2}$ Graduado, IFAL-Campus Maragogi, biuaspec@hotmail.com

${ }_{3}^{3}$ Mestre, Instituto de Pesquisa Agropecuária de Pernambuco, levandro@hotmail.com

${ }^{4}$ Doutor, UFRPE, dmeneufrpe@gmail.com
} 
Seu cultivo vem alcançando bons índices de produtividade e proporcionando renda nas pequenas propriedades. O consumo dessa hortaliça vem aumentando no Brasil, pois contém flavonoides, alcaloides e esteroides e suas raízes têm propriedades antioxidantes que podem diminuir o nível de colesterol (GONÇALVES et al., 2006; GOMES et al., 2012).

A berinjela tem sido alvo de várias pesquisas decorrentes da disseminação de suas propriedades medicinais junto à população, podendo ressaltar sua utilização para a redução das taxas de gordura e de colesterol no sangue (MARQUES, 2003). Assim, tem ocorrido aumento do consumo de seus frutos frescos, motivado pela maior exigência dos consumidores por produtos mais saudáveis e com propriedades medicinais (PRAÇA et al., 2004). Encontram-se preparações comerciais de extrato de berinjela indicadas para redução do colesterol, na forma de cápsulas e em formulações de outros produtos fitoterápicos (QUINTÃO, 2004).

A população também tem recorrido a tratamentos alternativos, naturais e de baixo custo, para o controle da dislipidemia, ou seja, nível elevado de gorduras no sangue, utilizando alimentos ricos em fibras, como a berinjela, para reduzir o nível de colesterol sérico (DERIVI et al., 2002). Neste caso, seu efeito medicinal ainda não está consolidado cientificamente, pois as pesquisas apresentam resultados divergentes quanto à sua eficácia no tratamento da dislipidemia (PRAÇA $e t$ al., 2004).

Observa-se interesse na comercialização de produtos moídos em formulações de alimentos alternativos como, por exemplo, hambúrgueres de berinjela. Por suas características nutricionais, a farinha de berinjela desponta como um ingrediente alimentar altamente desejável para enriquecer outros alimentos. Dentre os atrativos da berinjela, pode se ressaltar o elevado teor de fibra alimentar total, aproximadamente $40 \%$, o que permite que essa farinha possa ser utilizada na elaboração de produtos de panificação e massas alimentícias, ampliando a oferta de produtos integrais. Esse novo nicho de mercado pode atingir tanto consumidores sadios, que priorizam bons hábitos alimentares, como aqueles que apresentam algumas patologias, tais como, constipação intestinal, alto nível de colesterol no sangue e obesidade (PEREZ, 2007).

O melhoramento de $S$. melongena é bastante desenvolvido em vários países como Turquia, Índia, China e Japão. No entanto, cultivares desta espécie, muitas vezes têm níveis insuficientes de resistência a estresses bióticos e abióticos (SEKARA et al., 2007). Nos últimos trinta anos, muitos híbridos F1 com fenótipos diferenciados foram selecionados para características de interesse como precocidade, produtividade, ausência de espinhos e cor intensa (DAUNAY \& JANICK, 2007).

Cada sistema de cultivo apresenta um manejo diferenciado, seja no sistema convencional, orgânico ou no cultivo hidropônico. As alterações no comportamento relativo dos genótipos, em diferentes ambientes são geralmente observados, esse fenômeno é chamado de genótipo ambiente 
(GxA), e deve ser estimado pelos melhoristas para compreender o desempenho do genótipo em diferentes ambientes (KANDUS et al., 2010).

Este trabalho teve como objetivo avaliar o potencial produtivo de genótipos de berinjela no sistema de cultivo orgânico.

\section{Fundamentação Teórica}

A berinjela é uma planta perene que possui características arbustivas. O caule é semilenhoso, com altura variando de 1,0 a $1,8 \mathrm{~m}$, com intensa ramificação lateral conferindo-lhe aspecto de arbusto compacto. As raízes podem ultrapassar 1,0 $\mathrm{m}$ de profundidade. Suas folhas podem apresentar espinhos e o formato ovado ou oblongo-ovado. As flores são hermafroditas, com distribuição solitária ou em inflorescência do tipo cimeira. O tamanho varia de 3 a $5 \mathrm{~cm}$ de diâmetro. O cálice, com cinco a sete sépalas, frequentemente apresenta espinho. A corola é do tipo gamopétala, com cinco a seis pétalas de coloração lilás a violeta (FILGUEIRA, 2008).

Reproduz-se preferencialmente por autofecundação. O percentual de polinização cruzada natural varia com a cultivar e com outros fatores ambientais, com média estimada em $6 \%$ a $7 \%$, podendo, no entanto, chegar próximo de 50\% (MARQUES, 2003). Os frutos são grandes, do tipo baga, de formato variável: oval, oblongo, redondo e alongado. Apresentam uma grande diversidade de cores, resultante das diferenças entre a presença, quantidade e distribuição de pigmentos na pele (MUÑOZ-FALCÓN et al., 2009). A cor do fruto também é usada para estabelecer os diferentes grupos comerciais: preto, roxo, verde, listrado e branco. Durante as últimas décadas, berinjelas de cor escura foram predominantes nos mercados em maior parte da Europa e América do Norte e representam o tipo de exportação mais aceito no sul da Europa (DAUNAY,_2008).

A cor escura intensa nos frutos é essencial para o sucesso de cultivares comerciais. Por conseguinte, a identificação de fontes de variação para a pele escura é de interesse. A cor negra de berinjela é o resultado de acumulação de pigmentos de antocianina nos vacúolos de células do epicarpo. Quanto mais camadas celulares e quanto maior o acúmulo de antocianinas, mais escura é a cor (DAUNAY, 2007).

O cultivo de berinjela vem alcançando bons índices de produtividade e proporcionando renda nas pequenas propriedades. O consumo dessa hortaliça vem aumentando no Brasil por ser a ela atribuído um efeito hipocolesterolêmico, despertando o interesse de estudos que confirmem suas propriedades medicinais. Em sua composição apresenta diversos minerais, destacando-se o cálcio, ferro, fósforo, assim como vitamina B1 e B2 (MARQUES, 2003).

Produtos orgânicos têm o seu alicerce na maior conscientização dos consumidores que demandam alimentos saudáveis e seguros quanto à ausência de resíduos químicos e 
microbiológicos. Além disso, a sociedade vem se preocupando com os danos causados ao ambiente pelo uso abusivo de agrotóxicos na produção de alimentos. Para o setor produtivo, o maior atrativo da produção orgânica, inicialmente, está relacionado aos preços mais elevados alcançados no mercado, em comparação ao produto similar produzido por via convencional. No entanto, há também produtores que se interessam por esse sistema devido à possibilidade de diminuição de custos com insumos, pela conscientização da redução de impactos ambientais e melhor funcionamento dos agroecossistemas (SOUZA \& RESENDE, 2006). Ainda existem poucos estudos visando a recomendação de genótipos para o cultivo em sistemas orgânicos, sendo crucial o desenvolvimento de pesquisas que visem otimizar a relação genótipo $\mathrm{X}$ ambiente.

\section{Metodologia}

A pesquisa foi realizada entre os meses de dezembro de 2012 e maio de 2013. O experimento foi conduzido na Estação Experimental Luiz Jorge da Gama Wanderley, IPA, localizada em Vitória de Santo Antão, PE, situada na Latitude Sul de 8 8’ 00’ e Longitude Oeste de 35²2’00”, na Mesorregião da Mata Pernambucana.

Oito genótipos de berinjela - seis híbridos e duas cultivares de polinização aberta (Tabela 1), foram avaliados em três sistemas de cultivo, no delineamento de blocos casualizados. A parcela útil foi constituída por uma área de $4,8 \mathrm{~m}^{2}$ contendo seis plantas, transplantadas no espaçamento de 1,0 m x 0,8 m. As plantas foram irrigados através de sistemas de microaspersão.

Tabela 1. Genótipos utilizados na pesquisa, com suas características. Fonte: Própria.

\begin{tabular}{|l|c|c|c|c|}
\hline \multicolumn{1}{|c|}{ Genótipos } & Empresa & Cor & Cor do cálice & Formato do Fruto \\
\hline Chica (Híbrido) & Tecnoseed & Roxo-escuro & Verde-escuro & Oblongo \\
\hline Embu (polinização aberta) & Horticeres & Vinho-escuro & Verde-escuro & Oblongo \\
\hline Florida Market (Polinização aberta) & Feltrin & Roxo-escuro & Verde-escuro & Longo ovalado \\
\hline Ciça (Híbrido) & Hortivale & Roxo-escuro & Verde-escuro & Oblongo alongado \\
\hline Comprida (Híbrido) & Sakama & Roxo-escuro & Verde-escuro & Comprida \\
\hline Viollete (Híbrido) & Sakama & Roxo-claro & Verde-escuro & Oblongo \\
\hline Roxelle (Híbrido) & Sakama & Roxo-claro & Verde-escuro & Arredondado \\
\hline Blanca (Híbrido) & Sakama & Branca & Verde-claro & Oblongo \\
\hline
\end{tabular}

Para produção de mudas, foram utilizadas bandejas de poliestireno expandido de 128 células contendo substrato comercial e pó de coco na proporção de 1:1. Foram semeadas três sementes por célula e efetuadas o desbaste 14 dias após a semeadura, deixando uma planta em cada célula. $\mathrm{O}$ transplante das mudas para o local definitivo ocorreu quando as plantas apresentavam seis folhas definitivas. Foram realizadas pulverizações semanais preventivas de defensivos para o controle de 
pragas e doenças.

A adubação constituiu-se na adição de $3 \mathrm{~L}$ de esterco de curral curtido e $50 \mathrm{~g}$ de torta de mamona em cada cova (CASTRO et al., 2005). Foram realizadas três adubações de cobertura com $36 \mathrm{~g}$ de torta de mamona em cada aplicação. Os tratos fitossanitários para este sistema se restringiram a pulverizações semanais com calda sulfocálcica (1\%) e óleo de nim (5\%).

A colheita foi realizada uma vez por semana, entre março e maio de 2013. Os frutos foram colhidos separadamente, quando atingiram o ponto máximo de crescimento. Para todos os frutos comerciais foram avaliadas as seguintes características agronômicas: massa média de frutos, comprimento, diâmetro, número de frutos por planta e produção por planta.

Os dados coletados foram submetidos à análise da variância de acordo com o delineamento experimental utilizado, considerando o modelo fixo. E as significâncias das análises de variância testadas pelo teste $\mathrm{F}$ e a comparação de médias pelo teste de Scott-Knott a $5 \%$ de probabilidade. As análises estatísticas foram realizadas utilizando o aplicativo genes (CRUZ, 2007).

\section{Resultados e Discussão}

As estimativas com relação à análise dos genótipos foram significativas pelo teste de $\mathrm{F}$ a 5 $\%$ de probabilidade para todas as características avaliadas. Isto evidencia a existência de variabilidade genética para as demais características entre os genótipos utilizados. Essa significância implica também no desempenho dos híbridos e cultivares de polinização aberta (Tabela 2). Os coeficientes de variação foram baixos para o diâmetro médio do fruto-DMF 8,75\%. As demais características apresentaram coeficientes de variação entre 14,75\% e 24,84\%.

Tabela 2. Valores dos quadrados médios para diâmetro médio dos frutos em cm (DMF), comprimento médio dos frutos em cm (CMF), massa média dos frutos por planta em g (MMF), número de frutos por planta (NMF), produção média de frutos por planta em $\mathrm{Kg}$ (PMF) de genótipos de berinjela em cultivo orgânico. ${ }^{* *}$ Significativo a $1 \%$ e ns não significativo pelo teste de F. Fonte: Própria.

\begin{tabular}{|l|l|l|c|c|c|c|}
\hline \multirow{2}{*}{ FV } & \multirow{2}{*}{ GL } & \multicolumn{5}{|c|}{ QM } \\
\cline { 3 - 7 } & & DMF & CMF & MMF & NFP & PMF \\
\hline & & 0,47 & 9,81 & 875,00 & 5,68 & 0,46 \\
\hline Genótipos & 7 & $16,65^{* *}$ & $197,94^{* *}$ & $27448,81^{* *}$ & $17,95^{* *}$ & $3,40^{* *}$ \\
\hline Resíduo & 35 & 0,38 & 9,04 & 1168,81 & 5,98 & 0,64 \\
\hline CV (\%) & & 8,75 & 21,14 & 14,17 & 18,24 & 24,84 \\
\hline
\end{tabular}

Ocorreram diferenças significativas entre as médias para as características avaliadas (Tabela 3), indicando uma ampla faixa de variação fenotípica em os genótipos utilizados no experimento. 
Os híbridos Viollete, Blanca e Roxelle, apresentaram os maiores valores para característica diâmetro do fruto. O híbrido Comprida apresentou o maior comprimento de frutos com média de 28,20. Este híbrido é muito utilizado na culinária por seu formato facilitar a obtenção de fatias para confecção dos pratos.

Tabela 3. Estimativas da média para diâmetro médio dos frutos em $\mathrm{cm}$ (DMF), comprimento médio dos frutos em cm (CMF), massa média dos frutos por planta em g (MMF), número de frutos por planta (NMF), produção média de frutos por planta em Kg (PMF) de genótipos de berinjela avaliados em sistema orgânico. ${ }^{(1)}$ Médias seguidas de letras diferentes diferem entre si pelo teste de Scott-Knott $(\mathrm{P}<0.05)$. Fonte: Própria.

\begin{tabular}{|c|c|c|c|c|c|}
\hline & \multicolumn{5}{|l|}{ Caracteres } \\
\hline Genótipos & ${\text { Diâmetro }(\mathrm{cm})^{1}}^{1}$ & $\begin{array}{l}\text { Comprimento } \\
(\mathrm{cm})^{1}\end{array}$ & $\operatorname{Massa}(\mathrm{g})^{1}$ & $\begin{array}{l}\text { Número de frutos } \\
\text { por planta }{ }^{1}\end{array}$ & $\begin{array}{l}\text { Produção } \\
{\text { (kg/planta })^{1}}^{1}\end{array}$ \\
\hline Comprida & $3,78 \mathrm{~B}$ & $28,20 \mathrm{Aa}$ & $158,33 \mathrm{D}$ & $15 \mathrm{~A}$ & $2,48 \mathrm{C}$ \\
\hline Chica & $6,48 \mathrm{~B}$ & $13,90 \mathrm{Ab}$ & $200,00 \mathrm{C}$ & $16 \mathrm{~A}$ & $3,27 \mathrm{C}$ \\
\hline Viollete & $6,95 \mathrm{~B}$ & $12,42 \mathrm{Ab}$ & $305,83 \mathrm{~B}$ & 13B & $3,87 \mathrm{~B}$ \\
\hline Roxelle & $8,58 \mathrm{~A}$ & $11,84 \mathrm{Ab}$ & $284,12 \mathrm{~B}$ & $12 \mathrm{~B}$ & $3,48 \mathrm{~B}$ \\
\hline Blanca & $8,68 \mathrm{~B}$ & $10,17 \mathrm{Ab}$ & $358,33 \mathrm{~A}$ & 12B & $4,78^{a}$ \\
\hline Ciça & $6,30 \mathrm{C}$ & $12,34 \mathrm{Ab}$ & $199,16 \mathrm{C}$ & 13B & $2,65 \mathrm{C}$ \\
\hline Embu & $6,92 \mathrm{~A}$ & $11,27 \mathrm{Bb}$ & $200,83 C$ & $14 \mathrm{~A}$ & $2,63 \mathrm{C}$ \\
\hline Florida Market & $7,75 \mathrm{~B}$ & $11,98 \mathrm{Ab}$ & $223,33 \mathrm{C}$ & $11 \mathrm{Bb}$ & $2,50 \mathrm{C}$ \\
\hline
\end{tabular}

Com relação à massa média dos frutos por planta (MMF), o híbrido Blanca apresentou a maior massa, acompanhado dos híbridos Viollete e Roxel. Já o híbrido Comprida ficou com o menor valor para massa média dos frutos. A característica massa média dos frutos apresenta-se como fator determinante para diagnosticar o desempenho das cultivares em diferentes ambientes (PROHENS et al.,2012).

O híbrido Ciça, liberado em 1991, apresenta boa aceitação por parte dos produtores e consumidores devido à qualidade do fruto, resistência às doenças e precocidade (RIBEIRO \& REIFCHNEIDER, 1999). No entanto, para produtividade, apresentou resultados abaixo de outros híbridos e superior as duas cultivares de polinização aberta.

Os híbridos Chica e comprida produziram a maior quantidade de frutos comerciais por planta, diferindo significativamente dos outros híbridos avaliados. Em contrapartida, o híbrido comprida apresentou a menor massa de frutos comerciais por planta. $\mathrm{O}$ número de frutos comerciais deve ser bem avaliado para seleção de sistema de cultivo, uma vez que o número de frutos por 
planta é o componente de rendimento de maior importância no melhoramento genético de berinjela (TATIS et al. 2009).

As diferenças encontradas entre os genótipos analisados estão relacionadas com as características intrínsecas de cada cultivar ou híbrido analisados. Estas características incluem a capacidade de absorção de água e nutrientes, a eficiência fotossintética e a partição de assimilados, as quais determinam as diferenças no crescimento da planta e a produção de frutos (ANTONINE $e t$ al. 2002). A produção de frutos comerciais por planta de Rochelle, Viollete e Blanca foram semelhantes às médias encontrados por Antonini et al (2002).

Já em relação Roxelle, este se destacou no sistema orgânico, produzindo com $284,12 \mathrm{~g}$ por fruto. No entanto, Apesar do bom resultado, o híbrido ainda não tem uma boa aceitação no mercado Nordestino, devido ao seu formato ser arredondado. Fato semelhante aconteceu com o híbrido Blanca que apresentou destaque tanto em relação à característica número de frutos comerciais por planta como também em relação à massa, onde apresentou o melhor resultado, alcançando massa por planta de 358,33 g, diferindo de maneira significativa dos demais genótipos.

\section{Conclusões}

Foi observada a superioridade na produtividade dos híbridos sobre as cultivares de polinização aberta no sistema de produção orgânica. Apesar do híbrido Ciça não apresentar a maior produção no experimento, este híbrido ainda tem grande importância para mesorregião de Vitória de Santo antão, por apresentar formato e coloração do fruto aceitos pelos consumidores.

Os híbridos Rochelle, Viollete e Blanca apresentaram os melhores resultados para massa dos frutos e produção de frutos por planta. Apesar desses híbridos apresentarem melhores resultados de produtividade, eles não são cultivados em grande escala em Pernambuco porque o formato e coloração dos frutos ainda não são bem aceitos pelos consumidores.

\section{Referências}

ANTONINI ACC; ROBLES WGR; TESSARIOLI NETO J; KLUGE RA. Capacidade produtiva de cultivares de berinjela. Horticultura Brasileira 20: 646-648, 2002.

CRUZ CD. Programa GENES: Aplicativo computacional em genética e estatística. Viçosa: UFV. 648p., 2007.

DERIVI, S.C.N.; MENDEZ, M.H.M.; FRANCISCONI, A.D.; SILVA, C.S.; CASTRO, A.F.; LUZ, D.P. Efeito hipoglicêmico de rações à base de berinjela (Solanum melongena, L) em ratos. Ciência e Tecnologia de Alimentos, v. 22, n. 2, p. 164-169, 2002. 
FILGUEIRA, F.A.R. Novo manual de olericultura: agrotecnologia moderna, produção e comercialização de hortaliças. Viçosa: UFV, 402 p., 2008.

DAUNAY M.C. Eggplant. p. 163-220. Eds J.Prohens and F.Nuez. New York, USA, 2008.

GOMES DP; SILVA AFD; DIAS DCF; ALVARENGA EM; SILVA LJD; PANOZZO LE. Priming and drying on the physiological quality of eggplant seeds. Horticultura Brasileira. v30, p. 484-488, 2012.

GONÇALVES GM; VIANA AP; REIS LSD; BEZERRA NETO FV; AMARAL JÚNIOR ATD; REIS LSD. Correlações fenotípicas e genético-aditivas em maracujá-amarelo pelo Delineamento I. Ciência e Agrotecnologia.v.32, p.1413-1418, 2008.

KANDUS M; ALMORZA D; RONCEROS RB; SALERNO J. Statistical models for evaluating the genotype-environment interaction in maize (Zea mays L.). Fyton. v. 79, p.39-46, 2010.

MARQUES, D.C. Produção da berinjela (Solanum melongena L.) irrigada com diferentes lâminas e concentrações de sais na água. Lavras: UFLA, 55 p., 2003.

MUÑOZ-FALCÓN, J.E.; PROHENS, J.; VILANOVA, S.; NUEZ, F. Diversity in commercial varieties and landraces of black eggplants and implications for broadening the breeders' gene pool. Annals of Applied Biology, Vol.3, p.453-465, 2009.

PEREZ, P.M.P.; GERMANI, R. Elaboração de biscoitos tipo salgado, com alto teor de fibra alimentar, utilizando farinha de berinjela (Solanum melongena, L.). Ciência e Tecnologia de Alimentos, v.27, n.1, p.186-192, 2007.

PROHENS J; PLAZAS M; RAIGÓN MD; SEGUÍ-SIMARRO JM; STOMMEL JR; VILANOVA $\mathrm{S}$. Characterization of interspecific hybrids and first backcross generations from crosses between two cultivated eggplants (Solanum melongena and S. aethiopicum Kumba group) and implications for eggplant breeding. Euphytica 186: 517-538, 2012.

PRAÇA, J.M.; THOMAZ, A.; CARAMELLI, B. O suco da berinjela (Solanum melongena) não modifica os níveis séricos de lípedes. Arquivos Brasileiros de Cardiologia, v. 82, n. 3, p. 269-272, 2004.

RIBEIRO CSDC; REISFSCHNEIDER F.. Avaliação do híbrido de berinjela'Ciça'por produtorese técnicos. Horticultura Brasileira 17: 49-50, 1999.

TATIS AH; AYALA CCE; CAMACHO EMM. Correlaciones fenotípicas, ambientales y genéticas en berenjena. Acta Agronómica 58: 285-291, 2009.

QUINTÃO, E.C.R. Da berinjela às estatinas: uma viagem entre ficção e realidade. Arquivos Brasileiros de Endocrinologia e Metabologia, v.48, n.3, 2004.

SEKARA, A; CEBUL. S.; KUNICKI, E. Cultivated eggplants - origin, breeding objectives and genetic resources, a review. Horticulturae, Ann.19/1, p. 97-114, 2007. 
SOUZA JD; RESENDE P. Manual de horticultura orgânica. Viçosa, MG:Aprenda fácil. 843p. 2006. 